\title{
Perceptions of Ethical Behavior in Ethical Mentoring Relationships Between Women Graduate Students and Faculty in Science and Engineering
}

\section{Ms. Laura Ann Gelles, Utah State University}

Laura Gelles is a second-year Ph.D. student at Utah State University in the Department of Engineering Education. Born in Reno, Nevada, she received her bachelor degree in Environmental Engineering from the University of Nevada Reno and her Master's degree in Environmental Engineering from the University of North Dakota. She is currently researching ethical mentoring and hidden curriculum in graduate women students in science and engineering. Her other research interests include mixed-methods research design, integrating sustainability and professional ethics into the engineering curriculum, and communication of science and engineering concepts to non-technical audiences.

\section{Dr. Idalis Villanueva, Utah State University}

Dr. Villanueva is an Assistant Professor in the Engineering Education Department and an Adjunct Professor in the Bioengineering Department in Utah State University. Her multiple roles as an engineer, engineering educator, engineering educational researcher, and professional development mentor for underrepresented populations has aided her in the design and integration of educational and physiological technologies to research 'best practices' for student professional development and training. In addition, she is developing methodologies around hidden curriculum, academic emotions and physiology, and engineering makerspaces.

\section{Dr. Marialuisa Di Stefano, Utah State University}

Marialuisa Di Stefano is a Postdoctoral Research Fellow at Utah State University, advancing research projects on bilingual education in New England and in Puerto Rico. She is an education researcher and advocates for historically marginalized groups in elementary education. Her research interest lies in bridging perspectives between transnational civic education, bilingual education, and STEM education, and how such intersections may lead to a more equitable education system. During the last 5 years, she worked specifically with emergent bilinguals in Utah and in the Boston area, looking at the ways students' funds of knowledge, especially languages and belonging, intersect with their identity development, and their understanding of mathematics and science contents. She approaches her study through a culturally sustaining pedagogy lens that she developed through her experience teaching, tutoring, and observing K-12 students in Italy and in the United States for the past 15 years. 


\title{
Perceptions of ethical behavior in ethical mentoring relationships between women graduate students and faculty in science and engineering
}

\author{
Work In Progress
}

\section{Introduction}

The purpose of this Work In Progress (WIP) qualitative study was to explore how underrepresented women graduate students and faculty in Science and Engineering understand and perceive what constitutes ethical behavior in a mentoring research relationship centered around the six ethical principles of Beneficence, Nonmaleficence, Autonomy, Fidelity, Fairness, and Privacy. This WIP paper focuses on the responses of eight graduate students and four faculty to six case studies that targeted a specific ethical mentoring principle, and it represents an expansion of a larger study currently under review. The goals of this WIP paper are to: (a) explore participant understanding of each ethical mentoring principle; (b) elucidate participant perceptions of ethical issues in six case studies; and (c) reveal what ethical behaviors participants expect from their respective mentor/mentee if they placed themselves in the situation of the case studies.

\section{Background}

The relationship between a faculty-advisor and a graduate student has been shown to be a determining factor of graduate student success [1], [2]. Advising relationships are typically formally assigned and structured so that they can help students adjust to the departmental culture and provide them with a role model, critical information, and an advocate for their professional success [3]-[5]. Advising, when described as exceptional or as a mentoring type of relationship, can foster a long-lasting and reciprocal relationship with professional, social, and emotional support [3] that is associated with greater well-being [6] and higher degree completion rates [2], [7]. Mentors help socialize graduate students into the professional, methodological, intellectual, and ethical norms of their discipline and department [3], [8]. This socialization can occur through communication of explicit information or through implicit messages [9].

Mentoring relationships, while typically viewed in a strictly positive regard [3], in some instances can become dysfunctional with negative outcomes [10]. In cases where dysfunctional mentoring may be present, there exists a relationship that is "unproductive or characterized primarily by conflict” [10, p. 45] where the needs of both mentor and mentee are not met [3]. In the latter case, negative consequences that impinges research productivity can occur.

This study begins to explore the perceptions graduate students and faculty in science and engineering carry about research relationships to help reveal hidden perspectives, principles, norms, and other factors that can hinder or risk inclusive, healthy, and productive research relationships. 


\section{Theoretical framework}

This work is centered around the theoretical framework of ethical mentoring. Ethical mentoring is defined as the "special relationship in which one person accepts the trust and confidence of another to act in the latter's best interest" [11]. Research relationships involves a duality of the trust and confidence [3], [12] between a mentor or mentee and is guided by six ethical principles:

(a) Beneficence (mentor/mentees obligation to promote best professional interests), (b) Nonmaleficence (avoidance of using mentor/mentees role for harm), (c) Autonomy (mentor/mentees avoidance of promoting dependency vs. independence), (d) Fidelity (mentor/mentees sense of loyalty), (e) Fairness (mentor/mentee safeguarding of equal treatment), and (f) Privacy (mentors/mentees avoidance to reveal sensitive material without consent). These six principles serve as a baseline to collect participant perceptions on about research mentoring relationships.

\section{Researchers' positionalities}

The authors of this work are underrepresented women within and outside of engineering who have experienced a wide range of mentoring styles in their time in higher education. As they have met and interacted with each other, they have acknowledged the importance of dual, equitable, and trustworthy research mentoring relationships. All three authors adhere to the principles stated in the aforementioned framework and aim to elevate the voices of women mentors and mentees across science and engineering disciplines, both of which are traditionally male-dominated and technically- and scientifically- demanding.

Acknowledging the researchers' positionalities means that there is a recognition that individual walks of life and current professional positions may bias the lens provided to these findings. On the other hand, the relationship and unique perspectives that each author brings, in terms of ethnicity, culture, gender, sexual orientation, and class [13], [14] also helps ensure that the data was cross-checked amongst the team for rigor and trustworthiness of the findings.

\section{Methods}

A qualitative case study design was used to explore the experiences and understanding of ethical mentoring principles for eight graduate students and four faculty within science and engineering using research mentoring relationships as a developmental factor [15]. The ethical mentoring principles were used to inform selection of vignettes or 'case studies' from Johnson's mentoring guide for higher education faculty [3]. This vignette technique was selected because it allows participants explore the attitudes, perceptions, beliefs, and norms [16] in a less threatening way and offers participants the option to talk about their personal experiences through the characters in the vignette [17].

The selection of case studies from Johnson's book [3] were done in a way to ensure maximum variation of responses by looking at both positive and negative traits and outcomes of mentoring. Six cases were selected from Johnson's book to correspond to six 'ethical mentoring' principles 
(Beneficence, Nonmaleficence, Autonomy, Fidelity, Fairness, and Privacy) that guides mentors to "consider their ethical obligations to mentees" [3, p. 123]. To minimize bias in selection, the case studies were discussed at length by the research team so that the most relevant scenarios for both graduate students and faculty in science and engineering were selected based on what has been published in the literature [3]. A summary of these case studies is provided in Table 1.

\section{Participant recruitment}

Eight female graduate students and four faculty were recruited as participants for this study from the Colleges of Science and Engineering at a western institution of higher education with varied roles (e.g., Full professor, Assistant professor, M.S. student, Ph.D. student, etc.) and disciplines (e.g. Biology, Aerospace Engineering, etc.) [18]. The intent of the qualitative research was not to generalize information, but rather to elucidate the particular and specific [19] among an acceptable sample size as suggested in qualitative research (i.e., 4-12 participants) [20] to ensure a rigorous and in-depth analysis of participant responses.

These participants were purposefully selected [21] based on their gender, discipline, and time within a research-advising relationship although over time, recruitment became based on convenience. To be eligible for the study, participants were required to be current tenure-track faculty or graduate student women working with a current advisor/advisee in a research project for six months or longer in Science or Engineering. Research relationships of less than six months were excluded because the beginning stages of an advising relationship is a time of adjustment, growth, and learning and a more mature relationship would provide richer information [3]. Male faculty and graduate students were excluded from this study because the intention was to highlight the experiences of women in Science and Engineering. Women graduate students with male mentors and women faculty with male mentees were included in this study.

Both domestic and international students participated in this study (three White U.S. citizens, two Latinas international students, one Asian international student, one White dual citizen U.S.Canada student, one Asian-American student) while faculty participants were predominantly domestic (three White U.S. citizens, one White dual citizen U.S.-Belgium). Mentees were predominantly doctoral students (five doctoral-Ph.D. students, two masters-M.S. students, and a concurrent M.S./Ph.D. student) with time in a research relationship ranging from six months to seven years. Faculty were at various stages of promotion (one Assistant Professor, one Associate Professor, and two Full Professors) with research experience ranging from ten to thirty years.

\section{Data collection and analysis}

Qualitative data was collected in the form of structured interviews, discussion boards, researchers' journals, and member-checking sessions. Participants were required to attend a structured interview session where they were asked some preliminary demographic questions about themselves and mentoring and were presented with six selected case studies taken from 
Johnson's book [3]. A voluntary online follow-up session was provided for the participants where they were asked to respond to two discussion boards on the general themes of this study's analysis. Pseudonyms were assigned to the twelve participants for their interviews to highlight commitment to the privacy and confidentiality of the participants, with the intent to "safeguard against unwanted exposure" [22, p. 145].

Interview data from audio and video recordings were transcribed and coded. All responses and memos were qualitatively coded using the six ethical mentoring principles as a basis for $a$ priori coding with additional considerations and openness to emerging themes. Also, multiple coding methods (holistic and thematic analysis) were used to "capture the complex processes or phenomena” in the data [23, p. 75]. Data was analyzed using MAXQDA 12 mixed-methods analysis software. Triangulation was done through multiple data sources (i.e., interviews and discussion boards), researchers' journals, interrater reliability checks, and regular memberchecking sessions which helped establish a communal code system to avoid errors of interpretation [24]. For all instances, interrater coder reliability exceeded 96\%.

\section{Results}

\section{A. A Priori Themes: Ethical Mentoring Principles}

A priori coding of the six ethical mentoring principles (Beneficence, Nonmaleficence, Autonomy, Fidelity, Fairness, and Privacy) revealed that both graduate students and faculty were most aware of the ethical mentoring principles of Beneficence and Fidelity and least aware of the principles of Fairness and Privacy. The ethical mentoring principles of Fidelity and Beneficence were prevalent across all case studies and participant groups suggesting a higher level of awareness of these principles. While each case study targeted a specific ethical mentoring principle, participants' responses could describe other ethical mentoring principles in their response to the case studies which frequently occurred for Beneficence and Fidelity across all participant populations, disciplines, and domestic/international status. When asked questions about mentoring research relationships before the case studies, participants frequently described Beneficence and Fidelity. Fidelity was coded in eleven out of the twelve participants' responses and Beneficence was coded in eight out of twelve participant responses before being exposed to the case studies. For example, when describing the positive attributes of a productive mentoring research relationship in her field, Valerie (faculty participant) described the ethical mentoring principle of Beneficence by stating,

From the mentor's standpoint, being able to either help the mentee achieve what he wants to do or might be able to help them find the people that can help them achieve their goals. And then positive attributes would be also then that the mentee is able to achieve those goals and is able to make that next step career wise or education wise of facilitating the career of that mentee, the career and educational goals of that mentee. (Valerie, Faculty, Interview \#1, Line 75). 
Table 1. Summary of Ethical Mentoring Principles and Case Studies.

\begin{tabular}{|c|c|c|}
\hline $\begin{array}{c}\text { Ethical } \\
\text { Mentoring } \\
\text { Principle }\end{array}$ & Definition & Case Study Summary \\
\hline Beneficence & $\begin{array}{l}\text { Mentor/Mentees } \\
\text { obligation to } \\
\text { promote best } \\
\text { professional } \\
\text { interests }\end{array}$ & $\begin{array}{l}\text { An assistant professor at a highly selective undergraduate technical university, Frank, offered energetic coaching } \\
\text { and sincere personal support to his engineering student mentees. Frank pushed and challenged his students to } \\
\text { develop confidence, face their anxieties, take risks, and rise to the level of excellence he expected. Frank } \\
\text { provided encouragement and rarely asked a student to do more than they could handle. As a result, Frank’s } \\
\text { students were often better prepared upon graduation. }\end{array}$ \\
\hline Nonmaleficence & $\begin{array}{l}\text { Avoidance of } \\
\text { using } \\
\text { mentor/mentees } \\
\text { role for harm }\end{array}$ & $\begin{array}{l}\text { A biology major student, Mary, selected a famous scholar, Dr. Scathe, as her major advisor because she was } \\
\text { impressed with his lectures and publications. Mary began to regret this decision when confronted with Dr. } \\
\text { Scathe's poor communication skills, emotional tirades, demeaning comments on her work and intelligence, and } \\
\text { complete unawareness of the corrosive effect of his behavior. }\end{array}$ \\
\hline Autonomy & $\begin{array}{l}\text { Mentor/Mentees } \\
\text { avoidance of } \\
\text { promoting } \\
\text { dependency vs. } \\
\text { independence }\end{array}$ & $\begin{array}{l}\text { One of the few full female history professors, Dr. Copie, encouraged a Ph.D. student, Sandra, to join her } \\
\text { research group. Over three years, Sandra began to feel that the more Dr. Copie invested in their relationship the } \\
\text { more pressure she felt to research only in Dr. Copie’s area of interest, to pursue a similar career, and to forego a } \\
\text { family until completion of her doctorate. While Dr. Copie was unaware of this, Sandra was certain that Dr. } \\
\text { Copie’s approval and interest hinged directly on Sandra’s willingness to follow Dr. Copie's career path. }\end{array}$ \\
\hline Fidelity & $\begin{array}{l}\text { Mentor/Mentees } \\
\text { sense of loyalty }\end{array}$ & $\begin{array}{l}\text { A new research fellow, Todd, hoped to receive career guidance and support from his supervisor, Dr. Scarce. } \\
\text { However, Dr. Scarce was rarely available and missed appointments that Todd scheduled. Dr. Scarce did not } \\
\text { return Todd's phone calls, only had time to talk between meetings and his lab, and seldom had time to help } \\
\text { Todd with questions about grants or to read drafts. When searching for a job, Todd asked other faculty for letters } \\
\text { of recommendation because he worried his supervisor hardly knew him. }\end{array}$ \\
\hline Fairness & $\begin{array}{l}\text { Mentor/Mentee } \\
\text { safeguarding of } \\
\text { equal treatment }\end{array}$ & $\begin{array}{l}\text { A Hispanic second year doctoral student complains to the department chair that he was discriminated against in } \\
\text { securing the faculty mentor of his choice. He has evidence that he has better grades, higher GRE scores, and } \\
\text { similar research interests and publications in a senior female professor's area of research. He had requested to be } \\
\text { advised by this professor, Dr. Select, but was told there were no openings. However, two months later, Dr. } \\
\text { Select accepted a White male advisee with no publications or experience in her area of research. The Hispanic } \\
\text { student believes the decision was based on race, attractiveness, or both. }\end{array}$ \\
\hline Privacy & $\begin{array}{l}\text { Mentors/Mentees } \\
\text { avoidance to } \\
\text { reveal sensitive } \\
\text { material without } \\
\text { consent }\end{array}$ & $\begin{array}{l}\text { An Associate professor, Dr. Allen, developed strong mentorships with the students in his department because of } \\
\text { his genuine concern for students. Students felt comfortable disclosing personal difficulties, conflicts, and } \\
\text { anxieties to which Professor Allen listened carefully and reassured the students. Occasionally, a student's } \\
\text { emotional difficulties appeared so severe he urged them to seek assistance at the university counseling center. } \\
\text { He made sure to have up to date counseling resources, helped schedule appointments, and made sure his } \\
\text { mentoring was not mistaken for a professional counseling relationship. }\end{array}$ \\
\hline
\end{tabular}


Fairness and Privacy were brought up the least by participants even in the case studies that directly targeted that principle. Some participants did not describe Fairness throughout the duration of their interview. The ethical mentoring principle of Privacy primarily appeared in the Privacy case study in relation to issues of confidentiality when a mentee shares their personal struggles with a mentor. Autonomy and Nonmaleficence were well understood and articulated by faculty and graduate student participants, however their opinions on the nuances of these principles was disparate. For Nonmaleficence, faculty focused on their relative position of power and the risk of that power being used to exploit students. Graduate students, on the other hand, mentioned the negative effects that an advisor's severe criticism can have on their well-being. For example, when commenting on the case study targeting Nonmaleficence, Bridgette (graduate student) stated:

We are always faced with a lot of anxieties regarding our work and everything. If somebody comes insulting my intelligence, which has really pushed me to a Ph.D., I feel it's kind of personal. Unless that person later makes me realize that it was just because he wanted me to do the work well, and then he appreciates that okay you're good but continuous demeaning comments might actually hamper the mental stability of a student. (Bridgette, Graduate Student, Interview \#1, Line 312)

When participants were directly asked if each case study contained ethical issues, a highly variable range of responses was given based on each case. Graduate students' perception of whether a case study contained ethical issues were highly disparate while faculty participants rarely disagreed. Additionally, faculty mentioned highly similar reasons for the case study containing ethical issues while graduate students cited different issues. The findings of participant perceptions of ethical issues within each case study are presented below.

\section{Beneficence}

Graduate students were in complete agreement that the Beneficence case study did not contain ethical issues. They perceived the mentor, Frank, who provided opportunities by pushing and challenging his mentees, to be a positive figure. They offered a few conditions where the situation could be unethical. These include if the mentor was pushing too hard and if the mentor is aware of a student's struggles and limitations and does not adjust to meet their needs. As opposed to the total consensus of the graduate students, this was the case where faculty had the most disagreement. While half of faculty stated there was no ethical issue present, the other half said that there maybe was. Like graduate students, they mentioned the ethical issue was pushing a mentee too far to their detriment. For example, Barbara (faculty) responded, "Um, probably, at least in the sense that if the students are reluctant to do things and the professor seems like he's trying to make them do it” (Barbara, faculty, Interview \#1, Line 60).

\section{Nommaleficence}


The Nonmaleficence case study had highly variable responses for graduate students and full consensus amongst faculty. In this case, a student chooses a prestigious advisor despite receiving warnings and continuously received "blistering and demeaning comments" about her work and intelligence [3, p. 213]. Faculty unequivocally saw this as an ethical issue that highlighted abuse of power. One faculty, Kendra, added that relative position of power implies ethical obligation by saying:

So he's in a position of power as an advisor. And so I think as an advisor, you do have some ethical obligations to the people that you're working with. So yeah, so I would say that the parts of it that I think is ethically wrong is the emotional tirades where he made blistering and demeaning comments about people's work and intelligence. That to me is ethically not okay as an advisor and a person in power over somebody else. (Kendra, Faculty, Interview \#1, Line 131)

Most graduate students saw this case study as an ethical issue citing the personal attacks on intelligence and compromising the emotional well-being of a student. One student, Chelsea saw differently stating, "I don't know if it's specifically ethical per se. I don't think this professor did anything blatantly wrong, um but, it’s not very nice.” (Chelsea, Graduate Student, Interview \#1, Line 210). When asked what advice she had for the individuals in the case study, this participant advised her to persist in the relationship because "that's probably not the last time she'll encounter that.” (Chelsea, Graduate Student, Interview \#1, Line 218). However, some graduate students were unclear if this was an ethical issue and mentioned it could be an issue if the advisor was aware of the emotional toll of his comments. On the other hand, faculty mentioned that this advisor's lack of awareness exacerbated the ethical issue.

\section{Autonomy}

When discussing a case study targeting Autonomy in which a Ph.D. student perceived her advisor only wanted her to research in her area of research and forego pursuing a family until completion of her doctorate, faculty were in total agreement that the case study contained ethical issues. Students, on the other hand, had widely varying opinions about the case study. Most graduate students, especially domestic graduate students, did not perceive there to be an ethical issue present. Most domestic graduate students deflected the issue of foregoing a family and only saw an issue with the situation if the mentor explicitly made it clear that the student could not pursue a family and articulated that it was normal to feel pressure to pursue similar research interests. International graduate students had highly variable opinions with some ignoring the issue of foregoing a family and focusing on possible negative career impacts, while another found the situation completely unethical because of the influence on personal life decisions. All faculty saw this case study as having ethical issues mostly relating to the power imbalance between faculty and student and the potential for abuse of power. Hailee (faculty) mused on how it is difficult not to give additional attention to a mentee who has similar research interests or 
professional goals, but when that crosses over into the personal realm it becomes unethical. Hailee stated:

So obviously if you're writing a paper, if you're doing analysis, being in line with your professor is probably a good thing. But in terms of where you go after you graduate, and whether you have a family or not, I don't think those are choices that your professor should have any real say in. I mean, obviously they can offer their opinion but they shouldn't be kind of withholding approval because if you're not making choices that they would make.” (Hailee, Faculty, Interview \#1, Line 199)

Faculty were in agreement that students should be allowed to make their own choices especially about their personal life, but related that they sometimes could get frustrated when a mentee did not follow their advice.

\section{Fidelity}

In the fourth case study presented to the participants, the scenario described a research fellow who was constantly trying to get time and attention from a supervisor that missed scheduled appointments and requests for letters of recommendation. Two graduate students found that the case absolutely had ethical issues stating the role of the supervisor comes with requirements to spend time with students and indicated that the supervisor was lying about his role as mentor because of his lack of availability. The other graduate students mentioned the possibility of ethical issues but struggled to reconcile the contractual obligation of a faculty supervisor towards a student with the definition of ethical. Kate (graduate student) highlighted her uncertainty by stating:

You know, I don't...again, ethical issues are difficult for me. I don't know, you know, as a mentor, as a faculty member, I don't think there are any hard and fast rules about how you have to mentor or how much time you have to invest in any one student, or students you mentor at all. So, you know, to me it seems unethical to take someone on and basically ignore them for the entire time that they're in their degree program, but I don't know that there's hard and fast rules that this person has violated, or things that are just really severely damaging like trash-talking your other student's work that we saw in the other example so, yeah, it's hard for me to comment on the ethical issues. I think it's a shame and a tragedy, but I don't know if this is like really crossing, um, you know some ethical guidelines within academia. (Kate, Graduate Student, Interview \#1, Line 516)

Most faculty were in agreement that this case presented a clearly ethical issue. They agreed that this mentor made a commitment and broke it and that mentoring and supervising imply a time commitment. Also, one faculty participant expanded this statement to indicate that when a 
mentee is missing research or career opportunities because of the supervisor's actions, that this should be also considered an ethical infarction, not just a moral one.

\section{Fairness}

In the Fairness case study, graduate students were once again split on whether the case study contained ethical issues while faculty agreed that it clearly contained ethical issues. When presented with the Fairness case study, which described a second-year doctoral student who complained to the department chair about possible racial discrimination in securing a faculty advisor, participants agreed that discrimination was unethical, but failed to find sufficient evidence in the case study that discrimination was occurring. Instead, they focused on whether the hiring decision was based on factors not included in the case study (i.e., funding, personality, conflict). Of those graduate students that agreed this case study contained ethical issues, they mentioned discrimination, racism, deception, and the possibility for inappropriate romantic relationship between the female advisor and male student. The other graduate students claimed it would only be an ethical issue if discrimination was proven. All faculty participants saw this case study as having ethical issues for disparate reasons. They all cited discrimination, both outright and subtle, and basing hiring decisions on non-academic factors. Additionally, some faculty mentioned the perception of hiring decisions and the impact of false accusations of discrimination on a faculty's career. Faculty acknowledged that discrimination may not have been occurring in the hiring decision but that did not exclude the case study from having ethical issues. For example, Valerie (faculty) states:

I mean, I understand that sometimes timing is everything so sometimes you're looking for people and you don't have candidates, sometimes you have candidates and you don't have money. And so the fact that the student, the original student, was not selected because there were no openings is real. But the problem is that when...later on, when there was money, that person was not even considered, and I think that's...and then that another person slotted in who basically had no credentials. And for me, that's a problem. (Valerie, Faculty, Interview \#1, Line 234)

\section{Privacy}

Graduate students and faculty participants were divided on whether the case where a professor developed strong mentorships with his students, listened to their personal difficulties, and referred them to counseling resources if necessary contained ethical issues. Most of the graduate students did not believe the case contained ethical issues and regarded the mentor in the case study positively. A few graduate students indicated it might contain ethical issues and saw the potential for breaking confidentiality, personal and professional boundary issues, and required legal reporting. For example, when asked if the case study contained ethical issues, Carrie (graduate student) stated: 
No, I don't. I'm not really sure if the fact that the Professor Allen was being, like, part of...I don't know, like, getting information of their personal life. I'm not sure if that is unethical. Because in the case of the Professor Allen, we can see that he knows how to manage that. But imagine that he didn't. Imagine that he was trying to be the counselor, well, then that is not ethical. So it's kind of confusing because this case is, like, okay everything is fine, but this act, it also could be something that can...it can go wrong, too, at the same time it can go wrong. So yeah, I think that probably that's not ethical at all. I mean, it's not, like, 100\% ethical. But I'm not sure. (Carrie, Graduate Student, Interview \#1, Line 334)

Faculty participants were in total agreement that the case study contained ethical issues. They were most concerned with how sharing personal information affected their ability to maintain personal and professional boundaries. They also mentioned reporting obligations and confidentiality as ethical issues for this case study.

\section{B. Emerging Theme 1: Expected ethical behaviors in research mentoring relationships} Participants revealed many ethical obligations for mentors and mentees when presented with the six case studies. Graduate students focused almost exclusively on what the ethical behaviors they would expect from their mentor if they were placed in a similar situation of the case study. Faculty participants, on the other hand, often mentioned both mentor and mentee obligations. A summarized table of participant responses to the question, What ethical behaviors would you expect from your mentor/mentee if placed in a similar situation to the case study? is provided in Table 2. While the responses were highly individualized and contextual, when considering the ethical mentoring principles, three themes emerged from our analysis. These themes are: (a) communication, (b) power, and (c) awareness.

\section{Communication}

Communication was identified as one of the critical ethical obligations of both mentors and mentees. Both faculty and graduate student participants cited communication as an essential part of a productive research relationship and highlighted how essential communication was to uphold their ethical obligations. This was especially prevalent in the Fairness case study where graduate students expected their mentor to reveal the reasons for hiring decisions and faculty expected students to speak to them first before raising the issue of discrimination with anyone else. For example, when speaking about the ethical behaviors they would expect from a mentor in the Fairness case study, Bailey (graduate student) stated: 
Table 2. Reported Expected Ethical Behaviors of Mentors and Mentees in Research Relationships in Science and Engineering.

\begin{tabular}{|c|c|c|}
\hline $\begin{array}{c}\text { Ethical Mentoring } \\
\text { Principle }\end{array}$ & Graduate Student Responses & Faculty Responses \\
\hline Beneficence & $\begin{array}{l}\text { Mentors should: } \\
\text { 1. Be challenging and encouraging. } \\
\text { 2. Be aware of student limitations so they do not push too far. } \\
\text { 3. Be understanding and caring of students' anxieties. } \\
\text { 4. Be aware of specific student needs including being } \\
\text { understand of students' anxieties. } \\
\text { 5. Adjust expectations when realizing they have pushed too } \\
\text { hard. } \\
\text { 6. Not exploit mentee work especially in publication authorship. }\end{array}$ & $\begin{array}{l}\text { Mentees should: } \\
\text { 1. Communicate if they are not ready for an activity or } \\
\text { challenge. } \\
\text { 2. Be hard working and effortful in meeting challenges. } \\
\text { 3. Be honest about deficiencies. } \\
\text { 4. Not cut corners or cheat when pushed too hard. } \\
\text { Mentors should: } \\
\text { 1. Not force students to be competitive with one another. } \\
\text { 2. Use a scaffolding approach to pushing and challenging } \\
\text { students. }\end{array}$ \\
\hline Nonmaleficence & $\begin{array}{l}\text { Mentors should: } \\
\text { 1. Not extend their criticism to personal traits (i.e. intelligence, } \\
\text { language, culture) of mentees especially in a way that } \\
\text { emotionally compromises a mentee. } \\
\text { 2. Be aware of how their actions affect mentees. } \\
\text { 3. Clarify expectations, explain their reasoning, and } \\
\text { communicate their intentions. } \\
\text { 4. Appreciate their mentees. } \\
\text { 5. Never speak poorly of their mentees in front of others. } \\
\text { 6. Possess emotional intelligence. }\end{array}$ & $\begin{array}{l}\text { Mentees should: } \\
\text { 1. Try to make their mentor aware of how their actions affect } \\
\text { them. } \\
\text { 2. Report behavior or seek outside help when constant verbal } \\
\text { attacks occur. } \\
\text { 3. Seek out a new mentor in this type of relationship. } \\
\text { Other Faculty or Deans should: } \\
\text { 1. Confront this type of mentor or report their behavior. }\end{array}$ \\
\hline Autonomy & $\begin{array}{l}\text { Mentors should: } \\
\text { 1. Show the same level of supportive mentoring and not } \\
\text { withhold power/opportunities despite different research interests } \\
\text { or career paths. } \\
\text { 2. Not pressure mentees to be just like them. } \\
\text { 3. Genuinely listen to and consider mentee ideas. } \\
\text { 4. Provide information about non-academic career options. } \\
\text { 5. Clarify their expectations and make subliminal pressures } \\
\text { more explicit. }\end{array}$ & $\begin{array}{l}\text { Mentees should: } \\
\text { 1. Communicate in a non-confrontational and non-judgmental } \\
\text { way their specific needs or if they have been pushed into an } \\
\text { undesirable path. } \\
\text { Mentors should: } \\
\text { 1. Be aware of the relative balance of power in their } \\
\text { relationship with a mentee. } \\
\text { 2. Give mentees freedom and let them make their own choices. }\end{array}$ \\
\hline
\end{tabular}




\begin{tabular}{|c|c|c|}
\hline Fidelity & $\begin{array}{l}\text { Mentors should: } \\
\text { 1. Provide mentees with time and attention; otherwise it is not a } \\
\text { mentoring or supervising relationship. } \\
\text { 2. Possess self-awareness and not take on mentees they do not } \\
\text { have time for. } \\
\text { 3. Be approachable and accessible. } \\
\text { 4. Be honest and inform their mentees of their lack of } \\
\text { availability and help them seek out other mentors. }\end{array}$ & $\begin{array}{l}\text { Mentees should: } \\
\text { 1. Demand time and attention when mentors do not give it. } \\
\text { 2. Not expect mentor to be available for everything. } \\
\text { 3. Communicate their expectations of their mentor. } \\
\text { 4. Seek out other mentors when necessary. } \\
\text { Mentors should: } \\
\text { 1. Only take on mentees if they have time and energy for them. } \\
\text { 2. Be open and honest about availability and make good faith } \\
\text { effort to keep appointments. }\end{array}$ \\
\hline Fairness & $\begin{array}{l}\text { Mentors should: } \\
\text { 1. Not discriminate in hiring decisions. } \\
\text { 2. Have explicit conversations with students to reveal reasoning } \\
\text { behind hiring decisions. } \\
\text { 3. Engage in an honest and objective evaluation of students and } \\
\text { not use non-academic qualifications for hiring decisions. }\end{array}$ & $\begin{array}{l}\text { Mentees should: } \\
\text { 1. Go to faculty first when rejected before raising the issue of } \\
\text { discrimination anywhere else. } \\
\text { Mentors should: } \\
\text { 1. Treat students with the same criteria and expectations in } \\
\text { hiring decisions. }\end{array}$ \\
\hline Privacy & $\begin{array}{l}\text { Mentors should: } \\
\text { 1. Know when or if to suggest counseling to mentees. } \\
\text { 2. Keep their mentees' information confidential. } \\
\text { 3. Be vigilant in maintaining professional and personal } \\
\text { boundaries. } \\
\text { 4. Not judge their mentees. } \\
\text { 5. Adjust work expectations if a mentee is struggling too much. } \\
\text { 6. Not pressure mentees to open up about personal problems. } \\
\text { 7. Care about their mentees and remember that emotions are } \\
\text { involved in mentoring. }\end{array}$ & $\begin{array}{l}\text { Mentees should: } \\
\text { 1. Be open and honest about their difficulties especially if it } \\
\text { affects their work performance. } \\
\text { 2. Help maintain personal and professional boundaries. } \\
\text { 3. Know about counseling resources and know when to utilize } \\
\text { them. } \\
\text { 4. Should be aware that mentors are not qualified to give them } \\
\text { counseling advice. } \\
\text { 5. Not exploit their personal problems as a way to avoid work. }\end{array}$ \\
\hline
\end{tabular}


I would expect my mentor to have a conversation with the student and, cause it doesn't sound like they were, they actually had a conversation about why he wasn't chosen. Um...so, well, a little bit how she had no current openings but I don't know if that meant that they had an explicit conversation or if was just um, so I feel like they should have a conversation, mostly. I think that would resolve what he thinks. (Bailey, Graduate Student, Interview \#1, Line 356)

Faculty participants mentioned that mentees should communicate in non-confrontational way with their mentors when they have been pushed too far, express their specific needs and expectations, and mention if a mentor's actions are causing them harm.

\section{Power}

The theme of power was more prevalent for faculty participants than for graduate students with emphasis on the relative balance of power between a mentor and a mentee. Power was seen by participants as something that could be given to a mentee in ways such as time and attention, through networking, or through letters of recommendation. Faculty participants frequently suggested that, when power was denied to mentees (e.g., not spending time with mentees), mentees should seek out other mentors. Faculty were particularly aware of their relative power dynamic with students in the Autonomy case study and how mentees can be unintentionally influenced by their mentor's approval and actions.

\section{Awareness}

Finally, awareness emerged not only as a theme but as an ethical obligation of both mentors and mentees. Both groups of participants reported that mentors should possess a high level of selfawareness and also be aware of the effects of their actions especially if they emotionally compromise a mentee. Graduate students had high expectations of mentor awareness, which include knowing when to suggest counseling for a mentee if needed and how far to push and challenge a mentee. For example, when discussing the ethical behaviors she expected of a mentor in the Beneficence case study, Lindsay (graduate student) stated:

But, I guess partly just being aware of like the students or my ability to deal things, you know. Like, it says he rarely made the mistake of asking a student to do more. Maybe just sort of, when he realizes he does make that mistake be able to back off and, um, have a conversation with the student sort of reassessing what they're able to do. (Lindsay, Graduate Student, Interview \#1, Line 219)

Faculty reported that they expected their mentees to help be aware of and maintain personal and professional boundaries and know when to seek counseling. Faculty participant's expectation of mentor awareness centered around being aware of their position of power. 


\section{Emerging Theme 2: Mentor and mentees' definition of 'ethical'}

Graduate students in particular lacked an understanding of what was considered ethical in a mentoring research relationship. Some participants did not know how to distinguish what was legal versus what was ethical. The debate between what can be considered ethical and what is recognized as legal has been long discussed and researched from a variety of perspectives in different fields, such as the politics of education [25], education in nursing [26], counseling and psychotherapy [27], and marketing [28]. The ethical versus the legal aspects of the mentoring relationship in higher education has not been addressed from a clearly defined epistemological standpoint. When developing the study, it was not anticipated that this theme would surface from the findings and warrants further exploration in future work. Below is an example of how the ethical vs. legal theme emerged from this study. When asked if the Beneficence case study contained ethical issues, Kate (graduate student) responded:

Um, I don't think it contains ethical issues. I mean, I'm not really well versed on what is or isn't ethical. I took the research and I don't know. What is that RCR [responsible conduct of research] training? Research? I took that like I don't know three years ago or something like that so...I don't really, I'm not the most up to date on what is or isn't ethical. To me it didn't seem like there were ethical issues in this case study. (Kate, Graduate Student, Interview \#1, Line 251)

In the Fairness case study, nearly all participants defaulted to the legal issue of discrimination and objectively proving if it occurred. For the Privacy case study, participants mentioned reporting obligations like Title IX where faculty have a duty to report if students have been sexually harassed. For example, Lindsay (graduate student) equated legal with ethical by saying:

I would assume that if he's being careful about that he's also being careful about like required reporting stuff cause clearly it's putting him in a situation where he's probably running into some stuff that he's then legally obligated to report. Although that's, I guess, technically more legal than ethical but it's legal because it's ethical. (Lindsay, Graduate Student, Interview \#1, Line 501)

Some participants even mentioned the lack of specific rules that govern mentoring research relationships at an institution as a source of confusion as to what was ethical. In a member checking session where participants were asked to comment on their institutional policies that relate to research or graduate students, they reported a lack of policies that governed conduct within research relationships and how mentoring was left out of faculty and student handbooks. Specifically, participants noted that the policies surrounding research focused on what not to do rather than what a positive mentoring relationship would look like. 


\section{Discussion}

There was a lack of consensus on what constitutes ethical mentoring in research relationships. While faculty participants have the most consensus they still collectively lacked an understanding of the principle of Fairness even when primed with a case study that targeted that principle. Graduate students, on the other hand, clearly had disparate views of what was ethical or unethical in a research relationship. Graduate students had most consensus on the ethical mentoring principles of Beneficence and Fidelity suggesting these principles are well understood or valued within their personal experiences. This aligns with a recent study on ethical mentoring where doctoral students in the natural and behavioral sciences emphasized Beneficence, Fidelity, and Fairness [29]. However, for issues like Nonmaleficence and Autonomy they lack a cohesive definition for what is acceptable and how a mentor's awareness affects the severity of an ethical infraction.

While both graduate students and faculty agree it is important to give each other the benefit of the doubt and assume behavior is not meant to be malicious or exploitive, hidden norms and expectations (i.e. hidden curriculum) of a research culture may be at play [30], [31]. When considering the "chilly climate" that has been described in engineering higher education culture [32], [33], graduate students could be receiving mixed messages as to whether their research advisors expect them to pursue similar research, career, and personal paths. The consensus of faculty and lack of consensus for graduate students suggests that faculty have learned what is ethical through experience. Interestingly, the Assistant Professor participant in this study voiced a different opinion about what was considered ethical in the case studies. It is likely that the assistant professor is in a transition period where she has yet to fully learn the hidden and unspoken rules surrounding ethical mentoring in research relationships.

This analysis also suggests that graduate students believe that their mentors should have a greater awareness of themselves and their mentees, which is supported by mentoring literature [34]. While graduate students expected mentors to inherently know how far to push or challenge a student, faculty related they could not know how far that was without the student explicitly communicating their strengths and limitations. Another area where graduate students and faculty have conflicting demands of each other is in the ethical mentoring principle of Privacy. Graduate students expect their mentors to have greater responsibility in maintaining personal and professional boundaries, knowing what counseling resources are available, and knowing when to suggest counseling. Faculty, however, expected their mentees to know what those counseling resources were and indicated that it was difficult to know when to suggest counseling. Considering science and engineering graduate students are less likely to seek mental health resources despite reporting similar rates of mental health problems than other disciplines [6], [35], and are more likely to rely on their advisors for help [36] students could be at greater risk when they face personal difficulties. 


\title{
Implications for Practice
}

The lack of explicit academic rules or policies surrounding ethical mentoring in research mentoring relationships limits the individual to define (or not define) what are appropriate codes of conduct and ethical behaviors within those relationships [8]. While an overall awareness of the consequences of an ethical infraction was present amongst graduate students and faculty, a lack of awareness of what constitutes ethical or not in a mentoring research relationship may increase the risk for unintentional harm due to ignorance or lack of experience [37].

Based upon the early findings, the authors opted to create a self-orienting table to help readers position themselves in their own mentoring research relationships. The hope is that by doing so, more awareness on the strengths and weaknesses of their mentoring relationships can be reflected upon and strategies, resources, or lines of communication for healthy, productive, and inclusive research relationships are sought (Table 3). While the work is not generalizable, our findings can be transferable to graduate students and faculty in higher education.

Table 3. Possible dynamics of ethical research mentoring relationships based upon the authors' findings in this work.

\author{
Healthy, Productive, and Inclusive Dynamics \\ - High Communication \\ - High Power Balance \\ - High Fidelity \\ - $\quad$ High Beneficence
}

Example Mentors/Mentees Courses of Action:

- Diligence in appointments and meeting deadlines

- There is a dual and respectful explicit advising on research roles and responsibilities

- There is a dual desire for advocacy in terms of their professional trajectories and intended career paths, even if they are not academically centered

- There are honest yet careful discussions about expectations, reasons for decisions, research struggles, and intentions to empower each other professionally
At-Risk Dynamics
Involves a combination of:
- Low OR High Communication
- Low OR High Power Balance
- Low OR High Fidelity
- Low OR High Beneficence

Example Mentors/Mentees Courses of Action:

- Clear advocacy and push for professional and research success but does not provide "big-picture" rationales for these initiatives

- No clear retrospection or communication when the research is becoming overwhelming or demanding enough that well-being may be jeopardized

- Regularly missed appointments without advanced notice or explanation; unproductivity and avoidance

- There are unclear or dishonest discussions about expectations, reasons for decisions, professional/research struggles, and professional intentions

- Feedback or ideas are somewhat considered but not fully valued

- Unclear or limited critical feedback and personal and professional boundaries when sharing confidential information 


\section{Unhealthy, Unproductive, and Exclusive Dynamics \\ - Low Communication \\ - Low Power Balance \\ - Low Fidelity \\ - $\quad$ Low Beneficence}

Example Mentors/Mentees Courses of Action:

- Does not maintain agreements or meet established deadlines

- Regularly missed appointments without advanced notices or explanations

- Unproductivity and avoidance

- Excessive micro-management or one-way power dynamic where information is kept by one individual

- Discussions about expectations, reasons for decisions, professional/research struggles, and professional intentions are seldom or lacking

- Exploitation of authorship and no transparency during the research process

- No clear communication amongst each other and individuals speak ill of each other in public

\section{Limitations}

This study was limited in that it was conducted on a narrow population in a predominantly white institution in the western United States. Recruitment of participants, while initially purposeful, became based on convenience throughout the institution. One interview was conducted with a bilingual participant who chose to express most of her responses in her native language. There could have been interpretation complications when analyzing this translated interview.

\section{Conclusions}

While these participants possessed a greater understanding of the ethical mentoring principles of Fidelity and Beneficence, their lack of awareness around the other ethical mentoring principles such as Fairness could result in possible dysfunction in their relationship. This paper proposes that a truly positive mentoring research relationship must not only adhere to six ethical mentoring principles but also must be one where both mentor and mentee are aware of and intentionally share their power by raising awareness through the tool of effective communication. While it is possible to adhere to other ethical mentoring principles while not sharing information or clarifying expectations through effective communication, it may not be possible to show Fairness without intentionally revealing the hidden norms and expectations [23] of academia so that power dynamics are shared and democratized. When power dynamics are shared in a research relationship, more ethical and long-lasting mentoring can occur.

\section{References}

[1]. B.J. Barnes, “The nature of exemplary doctoral advisors' expectations and the ways they May influence doctoral persistence,” Journal of College Student Retention: Research, Theory \& Practice, vol. 11, pp. 323-343, 2010

[2]. Y.F. De Valero, "Departmental factors affecting time-to-degree and completion rates of doctoral students at one land-grant research institution,” The Journal of Higher Education., vol. 72, pp. 341-367, 2001.

[3]. W.B. Johnson, On Being a Mentor, A Guide for Higher Education Faculty (2 ${ }^{\text {nd }}$ ed.). New York, NY: Routledge, Taylor and Francis Group, 2016. 
[4]. R.K. Grady, R. La Touche, J. Oslawski-Lopez, A. Powers, and K. Simacek, “Betwixt and between: The social position and stress experiences of graduate students,” Teaching Sociology, vol. 42, pp. 5-16, 2014.

[5]. C.J. Polson, “Adult graduate students challenge institutions to change,” New Directions for Student Services, vol. 102, pp. 59-68, 2003.

[6]. J.K. Hyun, B.C. Quinn, T. Madon, and S. Lustig, "Graduate student mental health: needs assessment and utilization of counseling services," Journal of College Student Development., vol. 47, pp. 247-26, 2006.

[7]. R. Sowell, Ph.D. Completion and Attrition: Analysis of Baseline Data, Washington, DC: Council of Graduate Schools, 2008.

[8]. M.F. King, On the Right Track: A Manual for Research Mentors. Washington, DC: Council of Graduate Schools, 2003.

[9]. S. Acker, "The hidden curriculum of dissertation advising," in The Hidden Curriculum in Higher Education, E. Margolis, Ed. New York, Routledge, 2001, p. 61-77.

[10]. W.B. Johnson, and J.M. Huwe, “Toward a typology of mentorship dysfunction in graduate school,” Psychotherapy: Theory, Research, Practice., Training, vol. 39, pp. 4455, 2002.

[11]. S.M. Plaut, "Boundary issues in teacher-student relationships”, Journal of Sex \& Marital Therapy, vol. 19, pp. 210-219, 1993.

[12]. D. Clutterbuck, "Step forward the ethical mentor", David Clutterbuck Partnership. [Online]. Available: https://davidclutterbuckpartnership.com/step-forward-the-ethicalmentor [Accessed: Dec. 20, 2017].

[13]. F. A. Maher, and M.K. Tetreault, M. K.,“Frames of positionality: Constructing meaningful dialogues about gender and race,” Anthropological Quarterly, vol. 66, pp. 118-126, 1993.

[14]. L.E. Villaverde, Feminist Theories and Education. New York, NY: Lang, 2008.

[15]. B. Flyvbjerg, "Case study," in The Sage Handbook Qualitative Research: Fourth Edition, N.K. Denzin and Y.S. Lincoln, Eds. Thousand Oaks, CA: Sage Publications, 2011, p. 301-316.

[16]. J. Finch, “The vignette technique in survey research,” Sociology, vol. 21, pp.105-114, 1987.

[17]. C. Barter and E. Renold, “The use of vignettes in qualitative research,” University of Surrey Social Research Update, vol. 25, 1999. [Online]. Available: http://sru.soc.surrey.ac.uk/SRU25.html [Accessed January 20th, 2018].

[18]. J. Creswell, Qualitative Inquiry \& Research Design: Choosing Among Five Approaches ( $3^{\text {rd }}$ ed.), Los Angeles, CA: Sage, 2013.

[19]. S. Pinnegar and J.G. Daynes, "Locating narrative inquiry historically: Thematics in the turn to narrative” in Handbook of Narrative Inquiry: Mapping a Methodology, D.J. Clandinin, Ed. Thousand Oaks, CA: Sage, 2007, pp. 3-34.

[20]. J.A. Hatch, Doing qualitative research in education settings. Albany, NY: State University of New York Press, 2002.

[21]. Glesne, C., (2006) Becoming Qualitative Researchers: An Introduction (3 ${ }^{\text {rd }}$ ed.). Boston, MA: Pearson Education, Inc.

[22]. C.G. Christians, "Ethics and politics in qualitative research," in The Sage Handbook of Qualitative Research: Third Edition, N. K. Denzin and Y. S. Lincoln, Eds., Thousand Oaks, CA, Sage, 2005, pp. 139-164. 
[23]. J. Saldaña, The Coding Manual for Qualitative Researchers ( $3^{\text {rd }}$ ed.). Los Angeles, CA: Sage, 2016.

[24]. Y.S. Lincoln and E.G., Naturalistic Inquiry. Newbury Park, CA: Sage Publications, 1985.

[25]. J. Gonzalo, "What does the right to education mean? A look at an international debate from legal, ethical, and pedagogical points of view," Studies in Philosophy and Education, vol. 20, pp. 213-223, 2001.

[26]. M. Smith, Legal, Professional, and Ethical Dimensions of Education in Nursing, $2^{\text {nd }}$ ed. New York, NY: Springer Publishing Company, 2012. [E-book] Available: ProQuest Ebook Central.

[27]. W.H. Van Hoose and J.A. Kottler, Ethical and Legal Issues in Counseling and Psychotherapy, $2^{\text {nd }}$ ed. San Francisco, CA: Jossey-Bass, 1985.

[28]. G.T. Gundlach and P.E. Murphy, "Ethical and legal foundations of relational marketing exchanges,” Journal of Marketing, vol. 57, pp. 35-46, 1993.

[29]. E. Löfström and K. Pyhältö, "Ethics in the supervisory relationship: Supervisors' and doctoral students' dilemmas in the natural and behavioural sciences," Studies in Higher Education, vol. 42, pp. 232-247, 2017.

[30]. E. Margolis and M. Romero, "The department is very male, very white, very old, and very conservative: The functioning of the hidden curriculum in graduate sociology departments,” Harvard Educational Review, vol. 68, pp. 1-32, 1998.

[31]. E. Margolis and M. Romero, "In the image and likeness...: How mentoring functions in the hidden curriculum," in The Hidden Curriculum in Higher Education, E. Margolis, Ed. New York, Routledge, 2001, pp.79-96.

[32]. B.R. Sandler, and R.M. Hall, "The campus climate revisited: Chilly for women faculty, administrators, and graduate students," Project on the Status and Education of Women, Washington, DC: Association of American Colleges, pp. 1-30, 1986.

[33]. G.M. Walton, C. Logel, J.M. S.J. Spencer, and M.P. Zanna, "Two brief interventions to mitigate a "chilly climate" transform women's experience, relationships, and achievement in engineering,” Journal of Educational Psychology, vol. 107, pp. 468-485, 2015.

[34]. W.B. Johnson, "The intentional mentor: strategies and guidelines for the practice of mentoring," Professional Psychology: Research and Practice, vol. 3, pp. 88-96, 2002.

[35]. J.K. Hyun, B. Quinn, T. Madon, and S. Lustig, "Mental health need, awareness, and use of counseling services among international graduate students," Journal of American College Health, vol. 56, pp. 109-118, 2007.

[36]. S.K. Gardner, "Contrasting the socialization experiences of doctoral students in high-and low-completing departments: A qualitative analysis of disciplinary contexts at one institution,” The Journal of Higher Education, vol. 81, pp. 61-81, 2010.

[37]. R. D. Brown, and L. Krager, "Ethical issues in graduate education: faculty and student responsibilities, The Journal of Higher Education, vol. 56, pp. 403-418, 1985. 